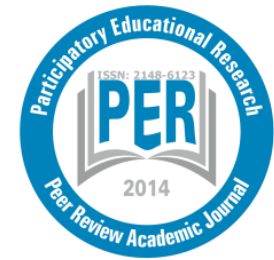

Participatory Educational Research (PER)

Vol. 6(2), pp. 144-157, December, 2019

Available online at http://www.perjournal.com

ISSN: 2148-6123

http://dx.doi.org/10.17275/per.19.18.6.2

\title{
The Implementation of WebQuest-supported Critical Thinking Instruction in Pre-service English Teacher Education: The Turkish Context
}

\author{
Dilan Bayram* \\ Department of English Language Teaching, Marmara University, Istanbul, Turkey \\ Gökçe Kurt \\ Department of English Language Teaching, Marmara University, Istanbul, Turkey
}

\section{Derin Atay}

Department of English Language Teaching, Bahçeşehir University, İstanbul, Turkey

\begin{tabular}{|c|c|}
\hline Article history & Critical thinking, a vital skill for the 21 st century, has become a \\
\hline $\begin{array}{l}\text { Received: } \\
24.10 .2019\end{array}$ & $\begin{array}{l}\text { desirable educational outcome by educators. Promoting students' } \\
\text { critical thinking has been a concern in various educational settings and }\end{array}$ \\
\hline $\begin{array}{l}\text { Received in revised form: } \\
25.11 .2019\end{array}$ & $\begin{array}{l}\text { the role of teachers is considered to be the most significant factor for } \\
\text { successful instructional implementations. The present study aims to } \\
\text { examine the effects of WebQuest-supported critical thinking instruction }\end{array}$ \\
\hline $\begin{array}{l}\text { Accepted: } \\
26.11 .2019\end{array}$ & $\begin{array}{l}\text { on the critical thinking disposition levels of Turkish pre-service } \\
\text { teachers (PTs) of English and to determine whether receiving }\end{array}$ \\
\hline Key words: & WebQuest-supported critical thinking instruction leads to a change in \\
\hline $\begin{array}{l}\text { Critical thinking; WebQuest; } \\
\text { pre-service teachers of English }\end{array}$ & $\begin{array}{l}\text { the PTs' understanding of critical thinking. Data were collected from } 60 \\
\text { freshman PTs studying at a state university in Istanbul, Turkey. Thirty } \\
\text { PTs were assigned to the experimental group and received WebQuest- } \\
\text { supported critical thinking instruction, while } 30 \text { PTs were assigned to } \\
\text { the control group and received traditional text-only instruction. The } \\
\text { study lasted seven weeks and data were collected by means of the } \\
\text { Turkish version of the California Critical Thinking Disposition } \\
\text { Inventory and semi-structured focus group interviews conducted before } \\
\text { and after the treatment. Findings revealed that the WebQuest-supported } \\
\text { critical thinking instruction produced statistically significant differences } \\
\text { in the PTs' critical thinking disposition levels and the PTs demonstrated } \\
\text { clearer awareness of critical thinking at the end of the study. }\end{array}$ \\
\hline
\end{tabular}

\section{Introduction}

The concept of critical thinking has been defined by various scholars in different disciplines. For example, Facione, Facione, and Giancarlo (1996) refer to critical thinking as "higher order reasoning used in reaching professionally informed judgments in high-stakes, time constrained, and many times, novel problem situations" (p. 41). According to Halpern (2003), critical thinking is "the use of those cognitive skills and strategies that increase the probability of a desirable outcome...purposeful, reasoned and goal directed- the kind of thinking involved in solving problems, formulating inferences, calculating likelihoods, and 
making decisions" (p. 5). Critical thinkers use these skills appropriately, without prompting, and usually with conscious intent, in a variety of settings.

Researchers indicate that critical thinking is more than the successful use of the right skill in an appropriate context. It is also an attitude or disposition to recognize when a skill is needed and the willingness to exert the mental effort needed to apply it (Mathews \& Lowe, 2011; Valenzuela, Nieto, \& Saiz, 2011). Thus, it is not enough to teach students the skills of critical thinking if they are not inclined to use them. To this end, critical thinking dispositions, e.g. open- and fair-mindedness, the propensity to seek reason, inquisitiveness, the desire to be well-informed, flexibility and willingness to accept and respect different opinions, need to be focused on (Lai, 2011).

Critical thinking has been widely acclaimed as an essential educational outcome for students at all levels and in all disciplines (Horvarth \& Forte, 2011; Reed \& Kromrey, 2001) since it helps students gain a deeper understanding of the presented information (Dwyer, Hogan, \& Stewart, 2012), develops their decision-making and problem-solving skills (Gambrill, 2006; $\mathrm{Ku}, 2009$ ), increases their motivation to learn and improve their ability of thinking and analyzing critically about their own learning (Phan, 2010). Hence, numerous studies have focused on different instructional interventions designed and implemented to promote critical thinking development of students. In that point, the role of teachers is considered to be the most significant factor in determining the success of such implementations (Kennedy, Fisher, \& Ennis, 1991). Thus, both in-service and pre-service teachers are expected to possess these skills and dispositions themselves in order to equip their students accordingly (Williams, 2005).

\section{Literature Review}

In the last decades, a number of studies on pre-service teachers' critical thinking have been conducted in many countries including Turkey. Some of these studies were descriptive in nature and aimed to determine the critical thinking levels of participants and make comparisons according to certain demographic and/or background variables. In an earlier study, McBride, Xiang, and Wittenburg (2002) worked with 202 pre-service physical education students in the USA and found their critical thinking levels as moderate. Gender was a significant factor in determining critical thinking levels of the participants. Similarly, Zayıf (2008) investigated critical thinking levels of 502 Turkish PTs from the Faculty of Education across different variables. Findings showed that the critical thinking levels of PTs were low in general and there were significant differences in their critical thinking levels according to gender, major, and grade level. Likewise, Tümkaya (2011) aimed to find out the critical thinking levels of Turkish PTs with respect to different variables. In total, 650 PTs from different departments participated in the study and it was concluded that the critical thinking levels of the participants were low and the ones having higher academic success were significantly better than the others regarding the critical thinking levels.

Considering the importance of critical thinking in the field of education, several experimental studies have investigated the effects of different instructional methods on critical thinking levels. For example, Kong (2006) examined the effects of a cognitive-infusion intervention on the critical thinking skills and dispositions of PTs from the primary school teaching program in Singapore. A total of 136 PTs participated in the study and they were assigned to the experimental and control groups. While the control group was instructed through traditional instruction, the experimental group was instructed through the Cognitive-Infusion 
Intervention Module (CIM) which focused on both theoretical (i.e. concepts, principles, generalizations, problems, facts, definitions, etc.) and practical (i.e. strategies and skills) dimensions of thinking. Results showed that the critical thinking skills and dispositions of the experimental group were significantly higher than the control group. Similarly, Akyüz and Samsa (2009) worked with 44 Turkish PTs from the Computer and Instructional Technology department and designed a blended learning environment through the use of chat rooms and forums. Students were required to participate in the classroom/online discussions, to reflect on the process, and to prepare a lesson plan on an instructional material presented in the curriculum. Results showed that there was no significant difference between the pre-test and post-test scores of the participants. In a more recent study, Arsal (2017) worked with 56 PTs in the science education program and investigated the impact of inquiry-based learning on their critical thinking. No significant difference occurred between the experimental and control group PTs in terms of their critical thinking dispositions at the end of the study.

The utilization of computer and interactive multimedia assisted teaching systems has been discussed to develop critical thinking skills (Sparks \& Kuenz, 1993; Yeh, 2000). The WebQuest, an inquiry-oriented web-based platform, has become prominent in many educational areas as a tool providing students with an opportunity to put critical thinking skills to use. WebQuest is "a scaffolded learning structure that uses links to essential resources on the World Wide Web and an authentic task to motivate students' investigation of a central, open-ended question, development of individual expertise, and participation in a final group process that attempts to transform newly acquired information into a more sophisticated understanding" (March, 2004, p. 3). A WebQuest is teacher constructed and includes five major sections: Introduction, Task, Process, Evaluation, and Conclusion. Introduction is the step in which background information related to the topic of the WebQuest is provided to prepare learners to the assigned task. Task is a description of the activity that learners are supposed to complete at the end of the process. Process is a detailed guideline that provides step-by-step instruction and pre-selected Internet resources to be followed in order to complete the assigned task. Evaluation informs learners about how their products will be assessed in the form of a checklist or a rubric. Finally, the Conclusion section gives learners a chance to reflect on both the process undertaken throughout the WebQuest and the product of it.

WebQuests are theoretically and empirically claimed to foster critical thinking of students if the sections are well-designed to expand the types of inquiry that can be undertaken in classes (Kundu \& Bain, 2006). In such an environment, learners' flexible use of knowledge is encouraged as it is net-structured rather than traditionally linear structured information, which promotes the individual's critical thinking (Zhou, Ma, Huang, Liang, Yue, \& Peng, 2012). Relatedly, Vidoni and Maddux (2002) compared the WebQuest format to a critical thinking framework proposed by Weinstein (2000) and concluded that WebQuests met all six of Weinstein's key concepts, i.e. skillful thinking, responsible thinking, non-routine thinking, employing criteria, self-correction, and sensitivity to context, and therefore could be seen as a powerful tool having the capacity to promote critical thinking skills in students.

\section{Rationale and Objectives of the Study}

The present study aimed to contribute to the relevant literature by suggesting an instructional model for the development of critical thinking dispositions of pre-service teachers (PTs) of English. More specifically, this study employed WebQuest as a medium of instruction and investigated its impact on critical thinking development of Turkish pre-service 
teachers of English. Turkish PTs of English were selected as the target group as (1) most of the studies on PTs' critical thinking development come from different subject areas with inconclusive results; (2) critical thinking levels and dispositions of PTs in Turkey have been generally found to be low; therefore, developing an instructional model to promote PTs' critical thinking skills in Turkey would guide teacher educators for designing similar professional development experiences for PTs; (3) The National Curriculum by the Ministry of Education in Turkey adopts a student-centered learning approach with a list of generic skills including critical thinking skills that needs to be treated in every course. Thus, developing critical thinking awareness of Turkish PTs would improve their successful implementation of the curriculum as teacher-related characteristics such as previous training and experience in critical thinking instruction are considered to influence the effectiveness of critical thinking interventions (Beyer, 2008; Pithers \& Soden, 2000).

The following research questions were specifically addressed:

(1) Will there be a statistically significant difference between the Turkish PTs of English who receive traditional instruction and those who receive WebQuest-supported critical thinking instruction in terms of their critical thinking disposition levels?

(2) Will there be a change in the PTs' understanding of critical thinking at the end of the study?

\section{Methodology}

\section{Design and Theoretical Framework}

Approaches used in critical thinking instruction generally follow Ennis' typology: general, infusion, immersion (Ennis, 1989). In the general approach, there is an explicit instruction on critical thinking and the objective is to teach critical thinking skills and dispositions independent from the subject matter content. The infusion approach combines instruction on the subject matter and critical thinking skills. Students are provided with explicit instruction on how to think critically in the context of specific subject matter. In the immersion approach, students get immersed in the subject matter instruction which implicitly involves teaching of critical thinking skills and dispositions.

The present study adopted a pre-test post-test quasi-experimental mixed methods design and followed the immersion approach in Ennis' typology for critical thinking instruction as a WebQuest was designed to provide "thought provoking kind of subject-matter instruction in which students do get deeply immersed in the subject, but in which general critical thinking principles are not made explicit" (Ennis, 1989, p. 5).

\section{Participants and Setting}

The seven-week experiment was conducted with 60 PTs enrolled at the English Language Teaching Department of a state university in Istanbul, Turkey. The participating PTs were all freshman students taking an Advanced Reading and Writing Course for three hours a week as a requirement of the curriculum. At the time of the study, the course was offered in four sections. Among these four intact classes, two of them were randomly selected for the study and assigned to control $(\mathrm{N}=30)$ and experimental $(\mathrm{N}=30)$ conditions, receiving traditional instruction and WebQuest-supported critical thinking instruction, respectively. 


\section{Procedure}

During the 7-week-long study, the task assigned to both the control and experimental groups was writing an argumentative essay on the topic of the death penalty. Both groups received instruction on argumentative essay writing. The instruction included building and/or activating PTs' background knowledge on the topic and guiding them in the process writing. For this purpose, while the experimental group PTs received WebQuest supported critical thinking instruction, the control group continued with traditional text-only instruction for three hours weekly during the study.

\section{Instruction in the Experimental Group}

A WebQuest about the death penalty was designed to promote critical thinking in the experimental group (see http://zunal.com/webquest.php?w=217046). The WebQuest followed the rubric developed by Puthikanon (2009) as follows: The main task/question should encourage the students to develop analysis, synthesis and evaluation skills; the roles/perspectives should provide multiple and conflicting perspectives; the process should require students speculate or infer about the similarities and differences of the information in the divergent sources to reorganize and critique them to form their own opinions, and the sources should contain useful/specific information about the topic. The WebQuest designed for the present study followed these items as follows:

In the first session, the instructor (the first author of the article) introduced the WebQuest to the experimental group PTs and showed them how to navigate through the pages. PTs were told to follow the instructions on the WebQuest closely and complete the assignments on time as described.

For the second session, PTs were assigned to visit the Process section on the WebQuest and follow the instructions. They were supposed to read an article on the history of death penalty, answer related comprehension questions and complete a researcher made survey about the topic individually. The survey aimed to make PTs question and form their opinions on the death penalty. During the class hour, PTs worked in groups of four and compared their opinions on the survey with their group members and tried to form a group opinion. Later, each group chose a spokesperson to share their group opinion with the rest of the class so that PTs could hear different opinions on the topic, which evoked conflict and let them to speculate about the similarities and differences. The next step described in the Process section of the WebQuest was forming a new group with four peers and choosing a role/perspective. The responsibilities of each role were clearly described on the WebQuest. The instructor went over the roles/perspectives during the class hour to clarify any unclear points. PTs formed their new groups and chose their roles/perspectives.

Following the second session, PTs, depending on the role/perspective they had chosen, read two more articles on the topic outside the classroom. In addition to these uploaded articles, PTs were encouraged to explore the websites linked to the WebQuest. Thus, they were expected to filter information to expand their understanding of the issue. Following their reading and exploration of relevant resources, PTs were asked to complete an outline about the readings and answer the reflection questions on the WebQuest. The questions aimed to develop their higher order thinking skills (i.e. analysis, synthesis, and evaluation). Sample questions included "What has the article convicted me of specifically?" (analysis), "If you were the writer of the article, what points could you omit? And what different points could you add to them? Why?" (synthesis), and "Would you recommend this article to other 
readers? Why or why not?"(evaluation).

When the PTs came to the third session, they discussed the topic in groups with the peers who had focused on the topic from the same perspective. Each group of students discussed the topic by using the outlines they completed at home. Following the discussions, PTs reformed groups to include four students, each of whom focused on the topic from a different perspective. They were not expected to convince their peers; instead, they were encouraged to present their reflections via sound justifications from the assigned texts and their own research.

After all these tasks, PTs were ready for the writing task. The WebQuest presented the PTs with the researcher-designed slides on the conventions of argumentative essay writing, links to websites tutoring how to write an argumentative essay and example essays on different topics. PTs studied these materials individually outside class and brought their argumentative essay outlines for the death penalty topic to the next session.

During the fourth session, PTs received individual feedback from the instructor on their outlines. Based on the feedback, they wrote their first drafts outside the class and received feedback from their peers in the next session (Week 5). Then, they revised their writing and delivered the second draft of their essays to the instructor and received individual feedback (Week 6). Finally, they handed in the final version of their essays for evaluation purposes (Week 7).

\section{Instruction in the Control Group}

In the first three weeks, the control group PTs read the same articles on the death penalty from different perspectives (i.e. victims' families, human rights activists, wrongfully convicted people's families, and religious functionaries), completed comprehension and vocabulary questions, and participated in classroom discussions. The classroom discussions were traditionally held as question-answer sessions. Last three weeks were allocated for the writing instruction. The instructor presented the conventions of argumentative essay writing in class. Then, similar to the process followed in the experimental group, PTs prepared outline for their argumentative essays, got teacher feedback on them and wrote first drafts accordingly. They received peer feedback on the drafts and revised their writing before they received instructor feedback on the second draft of their writing. Based on the feedback received, PTs finalized the essays and the process was completed.

\section{Data Collection and Analysis}

Data for the present study were collected by means of the Turkish version (Kökdemir, 2003) of the California Critical Thinking Disposition Inventory (CCTDI-T) (Facione \& Facione, 1992) and focus group interviews. The CCTDI-T consisted of 51 items on a 6-point likert response scale ranging from strongly disagree to strongly agree and six subscales, i.e. analyticity, open-mindedness, inquisitiveness, self-confidence, truth-seeking, and systematicity. The inventory was administered to both group PTs before and after the study. In the inventory, analyticity refers to be alert to potential problems, to anticipate the consequences, and to approach even challenging problems objectively within reason; openmindedness refers to be respectful and tolerant towards different opinions and to be sensitive to the possibility of one's bias; inquisitiveness refers to one's intellectual curiosity to learn something new without expecting any profit; self-confidence refers to one's trust to one's own reasoning process; truth-seeking refers to be eager to ask questions to find the truths and 
willing to keep questioning even in the times the opposing ideas are existent; and systematicity is about being organized and focused while making decisions by passing through knowledge-based steps (Kökdemir, 2003). The Cronbach alpha coefficient reported in Kökdemir's (2003) study was .88 and it was found to be .84 for the present study.

Because of the normal distribution of the scores according to the results of the KolmogorovSmirnov test $(\mathrm{z}=1.28 ; \mathrm{p}=.07)$, an independent samples t-test, as a parametric test, was applied to find out the differences between the experimental and control groups regarding their critical thinking disposition levels before and after the study. The significance level was set at $\mathrm{p}<.05$.

In order to have in-depth information about the possible changes in PTs' perception of critical thinking, semi-structured pre- and post-focus group interviews were conducted with 10 volunteer PTs from the experimental group. In both pre- and post-interviews, PTs were asked to define critical thinking; to identify characteristic of a critical thinker; to tell whether critical thinking is a teachable concept; and to tell how to teach critical thinking. The focus-group interviews were analyzed using pattern coding by organizing the data through discarding all irrelevant information and coding the raw data into conceptual categories, as suggested by Miles and Huberman (1994).

\section{Results}

\section{The Results of the California Critical Thinking Disposition Inventory Scores}

In the preliminary analyses, the pre-CCTDI-T scores of both groups were compared and no significant difference was found $(p<.05)$. In order to investigate critical thinking disposition levels of the PTs, an independent t-test was applied to both groups' gain scores in the CCTDI-T. As table 1 shows, the experimental group significantly outperformed the control group in their overall gain scores at the end of the treatment. In addition, the results of the t-tests indicated significant differences between the groups in terms of their gain scores in the subscales of inquisitiveness, analyticity, self-confidence, in favor of the experimental group $(p<.05)$ and truth-seeking, in favor of the control group $(p<.05)$. Although there were no significant differences between the groups regarding their level of critical thinking in systematicity and open-mindedness $(p>.05)$, the PTs in the experimental group had greater gains than the control group at the end of the study.

Table 1. Differences between the groups $(\mathrm{N}=60)$ in terms of their gain scores in CCTDI-T

\begin{tabular}{|c|c|c|c|c|c|c|c|}
\hline Sub-scale & Group & Test & $\mathrm{M}$ & SD & t-value & Df & $\mathrm{p}$ \\
\hline \multirow{4}{*}{ Inquisitiveness } & Fynerimental & Pre & 38.60 & 5.54 & \multirow{4}{*}{-2.46} & \multirow{4}{*}{43} & \multirow{4}{*}{$.018 *$} \\
\hline & Experimietital & Post & 41.53 & 5.67 & & & \\
\hline & \multirow{2}{*}{ Control } & Pre & 38.93 & 7.31 & & & \\
\hline & & Post & 37.80 & 8.68 & & & \\
\hline \multirow{4}{*}{ Analyticity } & \multirow{2}{*}{ Experimental } & Pre & 59.47 & 4.40 & \multirow{4}{*}{-2.86} & \multirow{4}{*}{58} & \multirow{4}{*}{$.006^{*}$} \\
\hline & & Post & 60.53 & 5.50 & & & \\
\hline & \multirow{2}{*}{ Control } & Pre & 58.90 & 6.52 & & & \\
\hline & & Post & 55.43 & 6.90 & & & \\
\hline \multirow{4}{*}{ Systematicity } & \multirow{2}{*}{ Experimental } & Pre & 24.73 & 3.57 & \multirow{4}{*}{-.67} & \multirow{4}{*}{58} & \multirow{4}{*}{.506} \\
\hline & & Post & 25.07 & 4.01 & & & \\
\hline & \multirow{2}{*}{ Control } & Pre & 24.83 & 3.87 & & & \\
\hline & & Post & 24.53 & 4.34 & & & \\
\hline
\end{tabular}




\begin{tabular}{|c|c|c|c|c|c|c|c|}
\hline \multirow{4}{*}{$\begin{array}{l}\text { Open- } \\
\text { mindedness }\end{array}$} & \multirow{2}{*}{ Experimental } & Pre & 51.73 & 5.06 & \multirow{4}{*}{-1.29} & \multirow{4}{*}{46} & \multirow{4}{*}{.205} \\
\hline & & Post & 51.17 & 7.31 & & & \\
\hline & \multirow{2}{*}{ Control } & Pre & 50.53 & 8.05 & & & \\
\hline & & Post & 47.47 & 8.76 & & & \\
\hline \multirow{4}{*}{ Truth seeking } & \multirow{2}{*}{ Experimental } & Pre & 26.47 & 5.40 & \multirow{4}{*}{2.22} & \multirow{4}{*}{58} & \multirow{4}{*}{$.030^{*}$} \\
\hline & & Post & 24.77 & 5.83 & & & \\
\hline & \multirow{2}{*}{ Control } & Pre & 24.87 & 6.11 & & & \\
\hline & & Post & 25.63 & 7.07 & & & \\
\hline \multirow{4}{*}{ Self-confidence } & \multirow{2}{*}{ Experimental } & Pre & 22.37 & 4.00 & \multirow{4}{*}{-2.83} & \multirow{4}{*}{48} & \multirow{4}{*}{$.007 *$} \\
\hline & & Post & 25.07 & 3.72 & & & \\
\hline & \multirow{2}{*}{ Control } & Pre & 23.00 & 6.36 & & & \\
\hline & & Post & 24.53 & 5.18 & & & \\
\hline \multirow{4}{*}{ OVERALL } & \multirow{2}{*}{ Experimental } & Pre & 223.37 & 17.23 & \multirow{4}{*}{-2.44} & \multirow{4}{*}{58} & \multirow{4}{*}{$.018^{*}$} \\
\hline & & Post & 228.00 & 21.33 & & & \\
\hline & \multirow{2}{*}{ Control } & Pre & 221.07 & 22.86 & & & \\
\hline & & Post & 213.47 & 27.62 & & & \\
\hline
\end{tabular}

$* \mathrm{p}<.05$

\section{The Results of the Focus Group Interviews}

Focus group interviews were conducted with randomly selected 10 volunteer PTs from the experimental group, before and after the study, to identify any changes in PTs' initial perceptions of critical thinking.

Pre-focus group interviews indicated that the PTs found it difficult to define critical thinking. Their definitions were vague and mostly referred to the requirements for critical thinking instead. Open-mindedness, tolerance to different or conflicting opinions, and objectivity were among the common underlying prerequisites mentioned by the interviewees. On the other hand, once the post-focus group interviews were analyzed, it was seen that the PTs could elaborate their definition of critical thinking as follows:

Critical thinking means creating one's own ideas by evaluating multiple perspectives objectively.

It is the process of forming the third view by synthesizing two different ideas with an open-mind and sound justifications.

When the PTs were asked to identify characteristics of a critical thinker, being objective, open-minded, tolerant, and unprejudiced emerged in both pre- and post-interview sessions. Additionally, PTs mentioned being knowledgeable, curious and skeptical as the required characteristics for a person to become a critical thinker for the first time in the postinterviews. Here are the PTs' comments illustrating these points:

To think critically, a person should have enough information or background knowledge. Otherwise, how could it be possible to defend or rethink one's own position and refute/support the claims of others?

A person should be curious if he wants to be a critical thinker. If he is not curious about others' opinions, he is likely to be obsessed with his own ideas, which kills critical thinking. 
Critical thinker is a person who is questioning all the present ideas. Not only opposing ideas but also supporting ideas should be questioned by a person if he really wants to be a critical thinker.

The PTs, who claimed critical thinking is not teachable, supported their position on the assumption that critical thinking is an inborn capacity and some hereditary factors determine it. Some of their responses are presented below:

Critical thinking is like ... either you have it or not. We must accept the fact that some people are gifted, and others are not. That is so simple.

Although inborn capacity was accepted as a reason to refute the possibility of teaching critical thinking in the pre-interviews, mental capacity was stated as a condition which determined the level of learnability of thinking critically in the post-interviews.

We can definitely teach how to think critically to a person if we consider the requirements. However, level of acquisition is closely related to his mental capacity. In short, critical thinking is a teachable concept but learnability is quite related to the cognitive maturity of a person.

Some PTs underlined that critical thinking is an outcome and there is no prescription for it. These PTs stated that critical thinking eventually emerges only if two conditions are created: Promoting critical thinking characteristics in the environment in which people are brought up and giving them enough chance to develop these characteristics.

Critical thinking is possible to teach as long as a person is encouraged to express his ideas in a welcoming environment - he can become more tolerant to others' opinions and hence appreciate them.

Besides, in the post-interviews, the PTs suggested organizing debates and assigning various reading materials to present conflicting ideas as the critical thinking activities in the school context.

Another theme emerging in the pre-interviews was the age factor. The PTs who stated that critical thinking is a teachable concept claimed that age is a crucial point in this sense. They pointed out pre-school and primary school years as the most appropriate years to teach this skill. One PT stated that:

I can't give an exact age but if we can teach a child how to be objective and tolerant to others' opinions in his early years, maybe in primary school years, he is more likely to think critically in the following years.

The PTs' beliefs related to the age factor differed in the post-interviews. Many stated that the practice of teaching critical thinking is not specific to earlier ages, but it is also possible to teach it at university level or even at further stages.

I had believed that we had to teach critical thinking in pre-school years or maybe during primary school years before the project. Even high school years had seemed to be late to do this, however during the project I could see that people can learn how to think critically even in their university years as we did. 
Before the project, I had assumed that all of the victims' families supported the death penalty but after I read various sources, I saw that the reverse situation was also possible. This truly shocked me.

Finally, there is one theme emerged in just post-interviews: Having a critical thinker around as a role model. Below are some of the PTs responses underlining the importance of this point:

I think seeing critical thinkers around is important. In that way, an individual can observe and experience the standards and characteristics required for thinking critically in daily life.

To be able to teach how to think critically, the teacher should be a critical thinker himself. Otherwise, how can it be possible to create required conditions and guide the learner effectively?

\section{Discussion of the Findings}

The present study was designed to measure the efficacy of WebQuest-supported critical thinking instruction as applied to a reading and writing course in a pre-service English teacher education program. The WebQuest-supported classroom was compared a traditional text-only classroom in order to determine its effect on the critical thinking disposition levels of Turkish PTs of English and to determine whether receiving WebQuest-supported critical thinking instruction leads to a change in the PTs' understanding of critical thinking. Findings revealed that the overall critical thinking disposition levels of the experimental group PTs were significantly higher than the control group PTs, which is in line with the previous studies (Bizri, 2010; Kanuka, 2005; Murry, 2006; Puthikanon, 2009; Zhou et al., 2012). The experimental group PTs also demonstrated clearer awareness of the concept and provided more precise definitions at the end of the study, which confirms the study of Turuk-Kuek's (2010).

Regarding the sub-scales of the critical thinking scale, significant differences between the groups in inquisitiveness, analyticity, and self-confidence were found to be in favour of the experimental group. The PTs' sense of inquiry was encouraged by extra Internet research and reflection questions. Since nearly all of the reflection questions had why/why not parts, they also appeared to encompass the basic components of the analyticity sub-scale, i.e. the use of reasoning and evidence. Likewise, the experimental group PTs were encouraged to use their reasoning to compare different pieces of information in terms of their similarities and differences by means of considering different perspectives on the death penalty and examining multiple sources including conflicting ideas for a single perspective. Taking the student-centred nature of the WebQuest project into consideration, the experimental group PTs' improvement in the sub-scale of the self-confidence was expected. As they had the freedom to express their opinions in the discussion sessions throughout the treatment, they might have felt that their opinions were valued, which emerged in the focus group interviews. Moreover, taking the responsibility of their own learning during the treatment might have also fostered the PTs' sense of self-confidence.

Although there were no significant differences between the groups regarding their level of critical thinking in open-mindedness and systematicity, the PTs in the experimental group had greater gains than the control group PTs at the end of the study. The reason why the groups did not differ in the sub-scale of open-mindedness might be because of the fact that the 
control group PTs also read the articles from different perspectives on the death penalty. In that way, their tolerance to divergent views and sensitiveness to the possibility of their own biases, as stated in the description of the sub-scale of open-mindedness, might have also been encouraged. Furthermore, writing an argumentative essay required both groups to consider not only supporting but also opposing views to come to an ultimate decision. The nature of the argumentative essay might have also led the control group PTs to be "organized, orderly, focused, and diligent in inquiry", which is fundamental for the sub-scale of systematicity. Although the difference was not significant between the groups in terms of systematicity, the guided nature of the WebQuest and having sources relevant to their perspectives on it were highly appreciated by the experimental group PTs as they mentioned in the focus group interviews. The only sub-scale in which the control group PTs' scores significantly higher than the experimental group PTs at the end of the treatment was truth-seeking. Taking the description of this sub-scale, "being eager to seek the best knowledge in a given context", into consideration, the excessive number of the sources to be read might have overwhelmed the experimental group PTs and led to this result.

The PTs' initial limited understanding of critical thinking may be due to the emphasis on memorization and rote-learning instead of problem-solving, analysis and the logical evaluation of acquired knowledge in Turkish educational system. Moreover, the fact that the PTs were aware of the importance of objective evaluation and synthesis of multiple perspectives with sound justifications for thinking critically in their post-definitions might show that they regarded the idea of thinking critically as a process.

Most of the PTs were in favor of the idea that critical thinking can be taught and some mentioned that their opinions on the teachability of critical thinking changed positively based on their experiences during the project. This finding may imply that the PTs were aware of their improvement in terms of critical thinking and this positive experience let them reflect on the concept of critical thinking. Since they regarded critical thinking as teachable, they were willing to integrate it into their future teaching practices and suggested activities such as debates and assigning different sources which contain conflicting ideas. The PTs' opinions related to some factors such as age and inborn capacity of individuals influencing critical thinking ability also changed from pre-interviews to post-interviews thanks to their positive experience as learners. Consequently, they claimed that teaching critical thinking at further levels of education might be possible.

\section{Conclusion and Pedagogical Implications}

The present study adds to the growing field of literature about critical thinking. Furthermore, it confirms the findings of similar studies by presenting evidence for PTs' improved critical thinking disposition levels and clearer awareness of the concept.

Based on the findings of this study, we can make the following recommendations for teacher educators, in-service teachers and instructional material designers. The instructor in the present study designed the instructional materials and learning activities purposefully around the notion of critical thinking. Thus, with appropriate methods and materials, it is proved to improve almost all aspects of critical thinking even within a limited time. Hence, teacher educators should be familiar with the components of critical thinking and gradually integrate them into courses in the teacher education programs so that their students are likely to implement critical thinking in their future classrooms. Although the present study exemplified one specific tool (i.e. WebQuest) to develop critical thinking dispositions of PTs at one 
specific grade level (i.e. freshman year), teacher educators should be aware of the alternative tools and be able to choose the most suitable one according to the nature of their courses for different grade levels (i.e. sophomores, juniors, and seniors). In teacher education programs, a crucial issue is linking the theoretical knowledge with practical skills, thus critical thinking integration should include practical skills via lesson plans, micro- and macro-teaching applications. Based on the findings, in-service teachers can also focus their efforts on the components of critical thinking while selecting and using resources and adapting their teaching strategies in order to equip their students to think critically. Finally, the findings of this study also have implications for instructional material designers. They are expected to analyze different levels of implementation of critical thinking and the needs of all parties (teacher educators, PTs, and in-service teachers) to offer them appropriate and various related critical thinking-aware resources.

The present study has a number of limitations, too. First, because of the pre-determined syllabus of the course in which the treatment was conducted, the duration of the study was only seven weeks. If more time had been available, a pilot WebQuest could have been implemented to familiarize the PTs with the WebQuest-supported instruction procedures. Second, the sample size was relatively small with 60 total participants, which might create problem regarding generalizability of the results. Third, since the instructor of the course was also one of the researchers, the outcomes of the treatment may have been influenced by unintended bias.

For the present study, post-data were collected one week after the treatment. In further studies, the long-term effects of the training can be measured if a delayed post-test is administered. Moreover, future research can benefit from recorded classroom discussions to observe how PTs of English use critical thinking when completing a WebQuest task. In that way, how they interpret, analyze, synthesize, evaluate, and reflect on the information can be investigated in a more detailed manner.

\section{References}

Akyüz, H. İ., \& Samsa, S. (2009). The effects of blended learning environment on the critical thinking skills of students. Procedia-Social and Behavioral Sciences, 1(1), 1744-1748.

Arsal, Z. (2017). The impact of inquiry-based learning on the critical thinking dispositions of pre-service science teachers. International Journal of Science Education, 39(10), 1326-1338.

Aydede, M. N., \& Kesercioğlu, T. (2010). The effect of active learning applications on students' critical thinking skills. Dokuz Eylül University Buca Faculty of Education Journal, 27, 14-22.

Beyer, B. K. (2008). What research tells us about teaching thinking skills. The Social Studies, 99(5), 223-232.

Bizri, Z. A. (2010). The effect of language WebQuest on the higher order thinking skills of Lebanese high school students (Unpublished master's thesis). Lebanese American University, Beirut, Lebanon.

Dwyer, C. P., Hogan, M. J., \& Stewart, I. (2012). An evaluation of argument mapping as a method of enhancing critical thinking performance in e-learning environments. Metacognition and Learning, 7(3), 219-244.

Ennis, R. H. (1989). Critical thinking and subject specificity: Clarification and needed research. Educational Researcher, 18(3), 4-10. 
Facione, P. A., \& Facione, N. C. (1992). The California Critical Thinking Disposition Inventory. Millbrae, CA: The California Academic Press.

Facione, P. A., Facione, N. C., \& Giancarlo, C. A. (1996). The California Critical Thinking Disposition Inventory Test Manual. Milbrae, CA, California Academic Press.

Gambrill, E. (2006). Critical thinking in clinical practice: Improving the quality of judgments and decisions. New Jersey: John Wiley \& Sons, Inc.

Halpern, D. F. (2003). Thought \& knowledge: An introduction to critical thinking (4th ed). London: Laurance Erlbaum Associates Publishers.

Horvath, C. P. \& Forte, J. M. (2011). Critical thinking. Nova Science Publishers Incorporated.

Kanuka, H. (2005). An exploration into facilitating higher levels of learning in a textbased internet learning environment using diverse instructional strategies. Journal of Computer-Mediated Communication, 10(3). Retrieved from http://onlinelibrary.wiley.com/doi/10.1111/j.1083-6101.2005.tb00256.x/full

Kennedy, M., Fisher, M. B., \& Ennis, R. H. (1991). Critical thinking: Literature review and needed research. In Idol, L. and Jones, B.P. (Eds.). Educational values and cognitive instruction: Implications for reform. Hillsdale, N.J.: Lawrence Erlbaum.

Kökdemir, D. (2003). Decision making and problem solving under uncertainty (Unpublished doctoral dissertation). Ankara University, Ankara, Turkey.

$\mathrm{Ku}$, K. Y. (2009). Assessing students' critical thinking performance: Urging for measurements using multi-response format. Thinking Skills and Creativity, 4(1), 7076.

Kundu, R., \& Bain, C. (2006). WebQuests: Utilizing technology in a constructivist manner to facilitate meaningful preservice learning. Art Education, 59, 6-11.

Lai, E. R. (2011). Critical thinking: A literature review. Pearson's Research Reports, 6, 4041.

Marin, L. M., \& Halpern, D. F. (2011). Pedagogy for developing critical thinking in adolescents: Explicit instruction produces greatest gains. Thinking Skills and Creativity, 6(1), 1-13.

March, T. (2004). The learning power of WebQuests. Educational Leadership, 61(4), 42-47.

Mathews, S. R., \& Lowe, K. (2011). Classroom environments that foster a disposition for critical thinking. Learning Environments Research, 14(1), 59-73.

McBride, R. E., Xiang, P., \& Wittenburg, D. (2002). Dispositions toward critical thinking: The pre-service teacher's perspective. Teachers and Teaching: Theory and Practice, $8(1), 29-40$.

Miles, M. B., \& Huberman, A. M. (1994). Qualitative data analysis. Thousand Oaks, CA: Sage.

Murry, R. (2006). WebQuests celebrate 10 years: Have they delivered? Retrieved from http://citeseerx.ist.psu.edu/viewdoc/download?doi=10.1.1.502.1148\&rep=rep1\&type= pdf

Phan, H. P. (2010). Critical thinking as a self-regulatory process component in teaching and learning. Psicothema, 22(2), 284-292.

Pithers, R. T., \& Soden, R. (2000). Critical thinking in education: A review. Educational Research, 42(3), 237-249.

Puthikanon, N. (2009). Examining critical thinking and language use through the use of WebQuests in an EFL reading class (Doctoral dissertation). Available from ProQuest Dissertations and Theses database. (UMI No. 3390298)

Reed, J. H., \& Kromrey, J. D. (2001). Teaching critical thinking in a community college history course: Empirical evidence from infusing Paul's Model. College Student Journal, 35(2), 201-2015. 
Sparks, S. M., \& Kuenz, M. A. (1993). Interactive instruction in nursing and other health sciences: Review of evaluation instruments. US Department of Health and Human Services, Public Health Service, National Institutes of Health, National Library of Medicine.

Tok, E., \& Sevinç, M. (2010). The effects of thinking skills education on the critical thinking and problem solving skills of pre-school teacher candidates. Pamukkale University Journal of Education, 27(27), 67-82.

Turuk-Kuek, M. C. (2010). Developing critical thinking skills through integrative teaching of reading and writing in the $L 2$ writing classroom (Unpublished doctoral dissertation). Newcastle University, Newcastle, England.

Tümkaya, S., Aybek, B., \& Aldağ, H. (2009). An investigation of university students' critical thinking disposition and perceived problem solving skills. Eurasian Journal of Educational Research, 36, 57-74.

Valenzuela, J., Nieto, A., \& Saiz, C. (2011). Critical thinking motivational scale: A contribution to the study of relationship between critical thinking and motivation. Electronic Journal of Research in Educational Psychology, 9(2), 823-848.

Vidoni, K. L., \& Maddux, C. D. (2002). WebQuests: Can they be used to improve critical thinking skills in students? Computers in the Schools, 19(1/2), 101-117.

Williams, R. L. (2005). Targeting critical thinking within teacher education: The potential impact on society. The Teacher Educator, 40(3), 163-187.

Yeh, M. L. (2000). Critical thinking and computer. Nursing, 4, 15-26.

Zayıf, K. (2008). Critical thinking dispositions of teacher candidates (Unpublished master's thesis). Abant İzzet Baysal University, Bolu, Turkey.

Zhou, Q., Ma, L., Huang, N., Liang, Q., Yue, H., \& Peng, T. (2012). Integrating WebQuest into Chemistry classroom teaching to promote students' critical thinking. Creative Education, 3(3), 369-374.

Zohar, A., Weinberger, Y., \& Tamir, P. (1994). The effect of the biology critical thinking project on the development of critical thinking. Journal of Research in Science Teaching, 31(2), 183-196. 